\title{
Secondary Epileptogenesis in Frog Forebrain: Effect of Inhibition of Protein Synthesis
}

\author{
F. MORRELL, N. TSURU, T. J. HOEPPNER, D. MORGAN AND W. H. HARRISON
}

SUMMARY: Secondary epileptogenesis was induced in the hippocampal cortex of the paralyzed bullfrog by means of localized, unilateral, intermittent electrical stimulation (kindling). Stimuli were designed to yield a brief but definite after-discharge. In control animals a progressive increase in after-discharge duration occurred at the $l^{\circ}$ (stimulated) site and then at the $2^{\circ}$ site (contralateral hippocampus). Spontaneous epileptiform potentials (SEP's) occurred between stimuli, eventually independently on both sides.

Cycloheximide $(50 \mathrm{mg} / \mathrm{kg})$ caused 88 $99 \%$ reduction in protein synthesis, measured by ${ }^{14} \mathrm{C}$-leucine incorporation

RÉSUMÉ: Une épileptogénèse secondaire fut produite dans le cortex hippocampal de crapeaux paralysés, grâce à des stimulations électriques localisées, unilatérales et intermittentes (kindling), chez des animaux contrôles et chez des animaux traités à la cycloheximide. Cette substance ne produisit aucun changement dans l'électrogénèse nor- into brain protein. Cycloheximidetreated animals revealed no evidence of progressive prolongation of afterdischarge duration when subjected to the kindling procedure $(p=0.1205 \times 10-7)$. SEP's were reduced in the cycloheximide-treated animals, and confined to $1^{\circ}$ hemisphere $(p=0.6 \times 10-10)$.

Since cycloheximide did not disturb normal electrogenesis or disrupt the after-discharges, this experiment distinguishes processes dependent upon electrical events from those requiring macromolecular synthesis. Protein synthesis seems critical to the emergence of spontaneous and autonomous epileptiform behavior of neural aggregates.

male ou dans les "after-discharges", permettant ainsi une distinction entre les évènements dépendant de mécanismes électriques et ceux qui requièrent une synthèse macromoléculaire. Il semble donc que la synthèse protéinique soit critique à la génèse de comportements épileptiformes spontanés et autonomes des aggrégats neuronaux.
From the Dept. of Neurological Sciences, Rush Medical College, Rush-Presbyterian - St. Luke's Medical Center, Chicago, III. 60612 and Marine Biological Laboratory, Woods Hole, Mass. 02543.

Supported in part by USPHS Grant MH24069-04

Reprint requests to Dr. F. Morrell, Rush-Presbyterian - St. Lukes Medical Center, Chicago, Ill. 60612 U.S.A.

\section{INTRODUCTION}

Secondary epileptogenic lesions (SEL) are ganglionic networks exhibiting spontaneous abnormal paroxysmal discharges which are at least one synapse removed from a primary epileptogenic lesion (Morrell, 1960). Primary foci may be produced by local implantation of chronic irritants such as cobalt, alumina gel or penicillin, by local freezing (Purpura et al., 1972), or, as in the present experiment, by electrical stimulation. In man, similar focal epileptogenic lesions arise as a consequence of various kinds of traumatic, infectious, vascular and neoplastic processes. Whatever the agent or agency responsible for the primary lesion, the SEL arises as a direct consequence of its activity and only in areas connected with the primary site by relatively massive tracts. Once established, the SEL persists indefinitely even after complete removal of the primary focus (Morrell, 1960).

The mechanism by which the primary epileptogenic focus gives rise to the secondary is unknown. The original theory of continuous neuronal bombardment from primary to secondary site (Morrell, 1961) had to be modified when it was found that continuous electrical stimulation of one hemisphere did not engender SEL whereas intermittent stimulation at parameters which were otherwise the same did so (Morrell, 1973). The latter observation was, of course, part of Goddard's discovery (Goddard, 1967), later to be designated the kindling phenomenon (Goddard et al., 1969). As Goddard and Morrell (1971) pointed out, the intermittency had to be such that brief (in the range of seconds) high frequency stimuli were delivered at 
long (not less than an hour) interstimulus intervals.

Earlier studies (Morrell, 1960, 1961) had indicated that the contralateral homotopic cortical SEL failed to develop if the interhemispheric commissures were sectioned, thereby neuronally isolating the primary lesion from what would otherwise be its target or recipient cortex. Conversely, there is now abundant evidence that in the presence of intact pathways, progressive and widespread dissemination of epileptogenic abnormality may result from a discrete chronic irritative lesion (Morrell and Florenz, 1958; Morrell, 1959, 1960, 1961; Morrell and Baker, 1961; Morrell et al., 1965; Wada and Cornelius, 1960; Wada, 1964; Guerrero-Figueroa et al., 1964a, 1964b, and see Wilder, 1972 for complete review). Dissemination took place in stepwise fashion over established synaptic pathways at rates relating not so much to distance as to number of intervening synaptic relays (Morrell and Tsuru, 1975). It seemed safe to conclude that information in some form was transmitted from primary to secondary sites and that the spread was not by diffusion but rather over specific nerve tracts. The slow time course of secondary epileptogenesis and the striking intermittency required in the kindling paradigm raised the possibility that a substance having a slower transit time than an action potential had to pass, perhaps by axonal transport, from primary to secondary region. Were this substance to be a protein or other complex molecule, in limited supply and requiring synthesis, one might expect that only brief periods of stimulation would be effective and that relatively long intervals, intervals reckoned in minutes rather than milliseconds, would have to intervene before the system could be activated again. This experiment tests the hypothesis that protein synthesis is essential for secondary epileptogenesis.

There is no dearth of agents which disrupt protein synthesis at various steps in the metabolic pathway. The major difficulty in the experiment was the selection of the proper organism and the proper technique for inducing epileptogenesis. A critical feature was that the full development of SEL must be possible within a time span during which the animal could survive nearly complete inhibition of protein synthesis.

Holubar et al., (1966) and Wilder and Morrell (1967a, b), using penicillin foci, demonstrated rapid development of secondary epileptogenesis in the forebrain of the frog. More recently Morrell and Tsuru (1974, 1975) applied the kindling technique to the hippocampal cortex of the bullfrog using an hourly stimulation regimen, and documented the emergence of independent $2^{\circ}$ discharge within 6-10 hours. Kindling, which employs local electrical stimulation as the "chronic irritant" of the primary focus, brings the entire process under much more rigorous experimental control than was possible with penicillin and other chemical agents. It also avoids the danger of physical diffusion of the epileptogenic agent. Thus it seemed appropriate, in the present context, to explore the SEL induced by kindling in the hippocampal cortex of the bullfrog.

We use the term "kindling", as did Goddard et al., (1969), to refer to all those "progressive changes that result from repeated electrical stimulation". We do not confine the term to the occurrence of behavioral convulsions even though clinical seizures were, historically, the original measure of kindling (Goddard, 1967). It is clear that the electrophysiological changes such as increase in afterdischarge (AD) duration and appearance of spontaneous epileptiform potentials (SEP's) represent essential elements in the later generation of epileptic behavior.

In the intact mammal bearing intracranial electrodes, brief, localized electrical stimulation of the brain at low current densities initially produces no alteration in behavior and little or no electrographic change. Repetition of the stimulus at regular intervals ranging from 1-24 hrs. results in gradual emergence of clinical convulsions, progressive augmentation in the duration of $A D$ and a widening of its anatomical distribution (Goddard, 1967; Goddard et al.,
1969; Goddard and Morrell, 1971; Morrell, 1969, 1973, 1974; Racine, 1972a, b, 1975; Tress and Herberg, 1972; Tanaka, 1972; Pinel et al., 1974; Wada and Sato, 1974). As noted above, the kindling technique has now been extended to the amphibian (Morrell and Tsuru, 1974, 1975). The central findings of the mammalian studies have been replicated, with the exception of the behavioral seizures (thus far, we have used paralyzed animals). The entire process occurs more rapidly in the frog and SEP's of a peculiar stereotyped character are a much more prominent feature.

In this report we shall first present a summary of the results of kindling in the frog and then discuss the alterations induced in that process by a potent inhibitor of protein synthesis.

\section{A. Physiological \\ METHODS \\ Initial studies (Morrell and Tsuru,} 1974, 1975) were carried out on 60 bullfrogs, Rana catesbeiana, weighing 100-200 gm, unanesthetized and partially immobilized with gallamine triethiodide (Flaxedil) at a dose of 0.5 $\mathrm{ml}$ per $100 \mathrm{gm}$. In subsequent experiments on another 85 frogs, spinal cord destruction was substituted for the Flaxedil with essentially the same results.

The frog was placed in a chamber partially immersed in amphibian Ringers Solution. The chondrocranium was opened, the dorsal hemispheres exposed and the skull fixed to a specially designed head holder. Bipolar stimulating electrodes $(0.1 \mathrm{~mm}$. diam., $1 \mathrm{~mm}$ tip separation) were applied to the hippocampal cortex of one hemisphere. Bipular recording electrodes consisting of $50 \mu$ tungsten wires were thrust into symmetrical regions of the two hippocampi.

Stimuli were delivered in a $2 \mathrm{sec}$. train once per hour. They consisted of biphasic pulse pairs, each pulse having a duration of $1 \mathrm{msec}$. and an amplitude of $100 \mu \mathrm{A}$. There was a $0.1 \mathrm{msec}$. delay between the two phases. Repetition frequency was 62.5 $\mathrm{c} / \mathrm{sec}$. The only parameter ever modifed was the magnitude of current, and this only rarely. If the initial $A D$ 
was over $20 \mathrm{sec}$. the current was slightly reduced; if it was under $5 \mathrm{sec}$. the current was increased. This never required more than 1-2 adjustments. In the great majority of animals initial AD duration varied between 6 and $12 \mathrm{sec}$.

\section{B. Biochemical}

Incorporation of ${ }^{14} \mathrm{C}$ labelled leucine into brain protein was our measure of protein synthesis. A modification of the method of Brink et al ., (1966) was used. The isotope $(2.5 \mu$ $\mathrm{Ci} / 10 \mathrm{gm}$ ) was injected intraperitoneally (IP). At the appropriate time after injection the frog was decapitated and the brain was removed, immediately weighed, and placed in an ice bath. The brain together with I $\mathrm{ml} 0.1 \mathrm{M} \mathrm{NaOH}$ was homogenized in a Duall tube with glass grinder. After transfer to a $15 \mathrm{ml}$ centrifugation tube $3 \mathrm{ml}$ of cold $12 \%$ trichloracetic acid (TCA) was added and the tube was placed in boiling water for $5 \mathrm{~min}$. and then in an ice bath for $15 \mathrm{~min}$. After centrifugation to separate the denatured protein the supernatant was removed from the pellet. The pellet was washed 2 times with $2 \mathrm{ml}$ cold $10 \%$ TCA and centrifuged each time. It was then dissolved with $1.0 \mathrm{ml}$ of Soluener 350 and the mixture added to $10 \mathrm{ml}$ scintillation fluid (tolueneethanol-POP-POPOP) in a scintillation vial. Samples were counted in a Tri-Carb liquid scintillation counter (Packard Tri-Carb 3003 Liquid Scintillation Spectrometer). The supernatant $(0.1 \mathrm{ml})$ was also placed in a scintillation vial, mixed with $10 \mathrm{ml}$ of scintillation fluid and similarly counted.

Detailed incorporation data were obtained using the grass frog, Rana pipiens, since many animals were required. However, the values were checked against individual Rana catesbeiana at selected intervals.

The incorporation data provided the baseline against which to measure the effect of an inhibitor of protein synthesis. Cycloheximide (Upjohn) $50 \mathrm{mg} / \mathrm{kg}$. was used as the inhibitor. At a series of times ranging from $30 \mathrm{~min}$. to $48 \mathrm{hrs}$. after IP injection of the antibiotic, the frogs received the usual dose of ${ }^{14} \mathrm{C}$ leucine and $2 \mathrm{hrs}$. later were decapitated and treated as above.

\section{RESULTS \\ 1. After-Discharge Duration}

After-discharge tended to be slower in the frog than in the mammal, was less likely to begin with low voltage fast rhythms, had fewer high frequency components and less complex wave-forms. On the whole these were minor differences; the general pattern of $A D$ and the change in duration with kindling were quite similar in frog and mammal. Figure 1 illustrates the progressive lengthening of $\mathrm{AD}$ duration in a Flaxedilized frog. Initially, AD duration was short (8 sec. on trial 2, Fig. 1A). On trial 3 (Fig. 1B) the duration was $13 \mathrm{sec}$, on trial 7 (Fig. 1C), $16 \mathrm{sec}$. and on trial 30 (Fig. 1D) it was $40 \mathrm{sec}$. On trial 7 there was a spike in the $2^{\circ}$ hemisphere (Fig. 1C, see arrow) which outlasted the events at the $1^{\circ}$ site. In trial 30 the pattern on the two sides differed and that in the $2^{\circ}$ hemisphere was often of higher amplitude. A more dramatic example of discharge at the $2^{\circ}$ region outlasting that at the $1^{\circ}$ may be seen in Figure 2. The AD began at the $1^{\circ}$ focus (Fig. 2A, Channel 3) and initially was of higher amplitude, more rhythmical, and individual components were sharper on that side. As the primary site discharge reached its peak amplitude and began to slow down (Fig. 2A, Ch. 3, extreme right), the discharge in the secondary region (Fig. 2A, Ch. 2) assumed a more rhythmical character entirely inde-
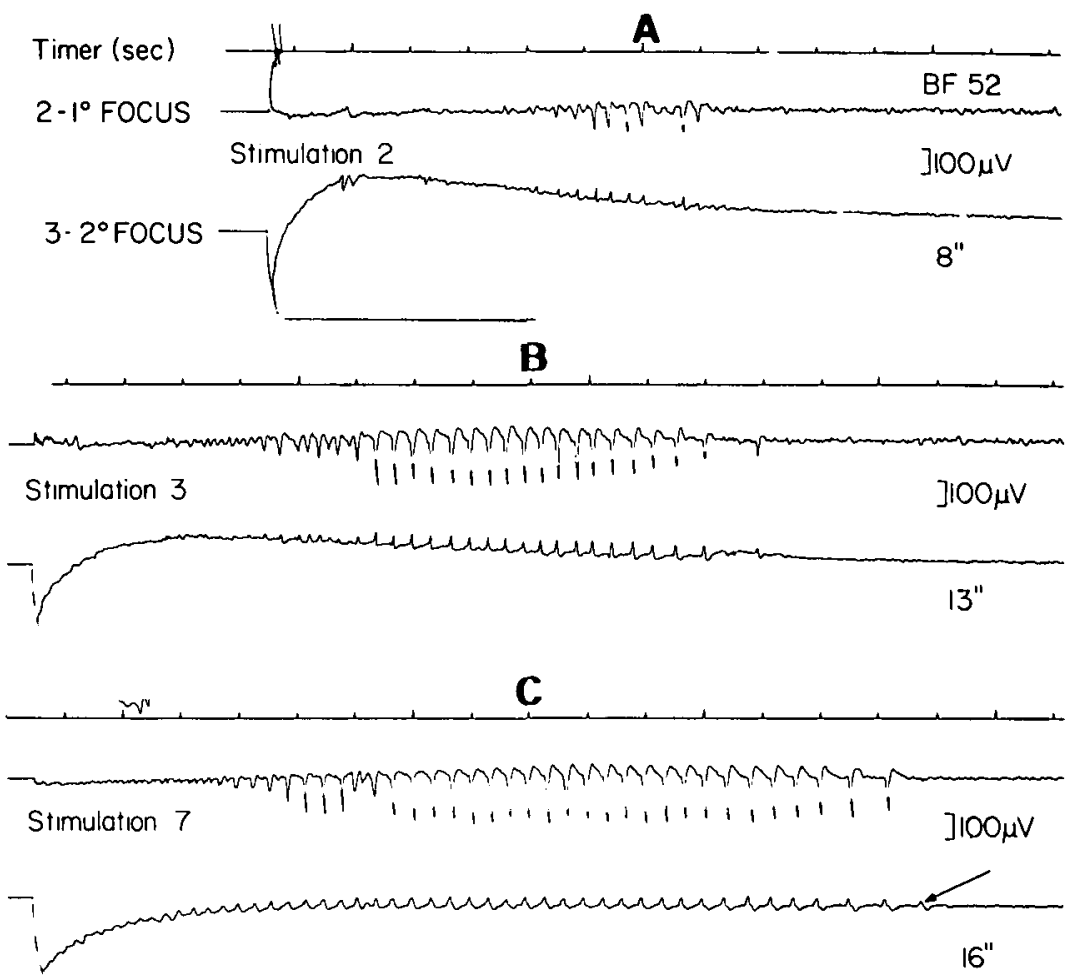

$\boldsymbol{\theta}$

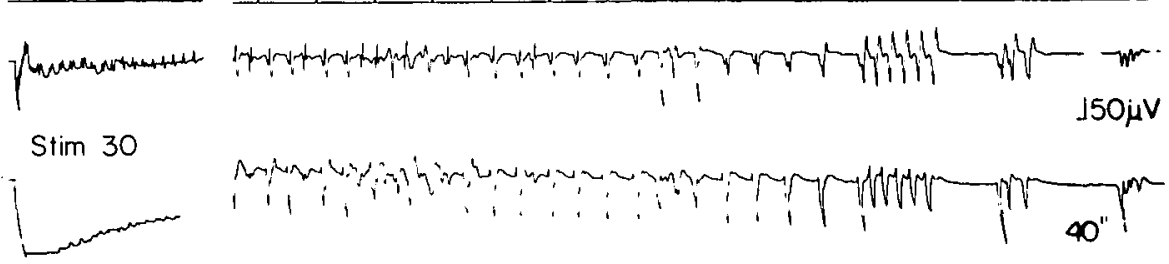

Figure 1-EEG tracings from the stimulated $\left(1^{\circ}\right)$ and non-stimulated $\left(2^{\circ}\right)$ hemisphere in the partially curarized bullfrog. The duration of the AD in seconds is given at the far right of each panel. In D, 21 sec. have been deleted; only the beginning, left and termination, right, are shown. Duration was always measured from the end of the 2 sec. stimulation (switching artifact) to the last spike in the sequence. From: Morrell and Tsuru, 1975. 


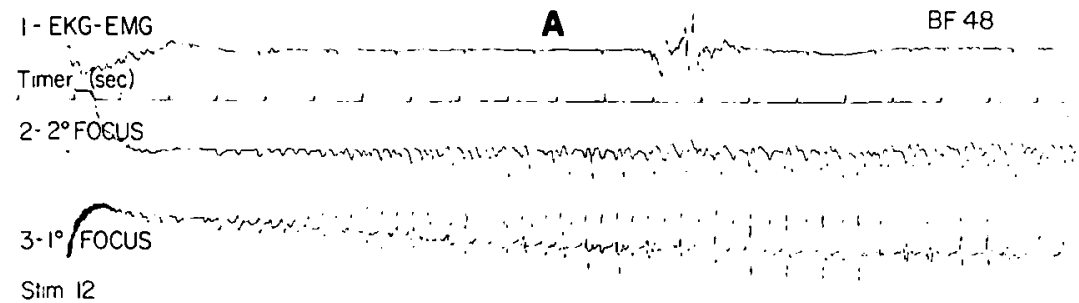

$\mathbf{B}$

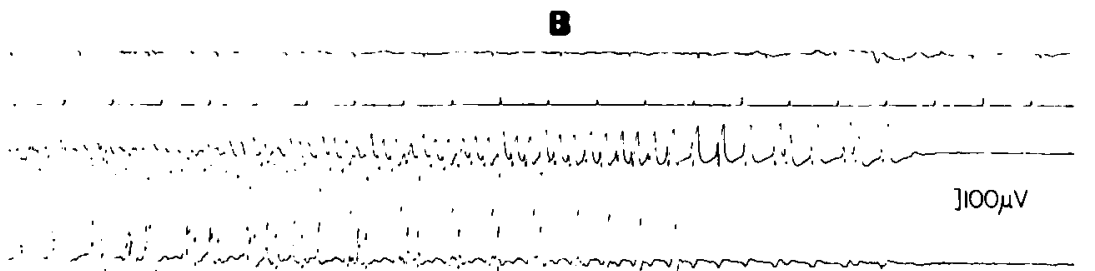

Figure 2-EEG records from the 12 th stimulation in another animal. Note that the positions of the channels deriving from $1^{\circ}$ and $2^{\circ}$ cortex are reversed in this record. From: Morrell and Tsuru, 1975.

pendent of the activity in Channel 3, and exhibited its own characteristic buildup (Fig. 2B, Ch. 2) which well outlasted the paroxysmal events in primary cortex (Fig. 2B, extreme right).

A typical individual curve of $A D$ duration as a function of number of trials is shown in Figure 3.

\section{Spontaneous epileptiform potentials}

Quite apart from the stimulusbound events just described, there occurred, in the interstimulus intervals, "spontaneous" high voltage paroxysmal transients which Morrell and Tsuru (1975) designated spontaneous epileptiform potentials

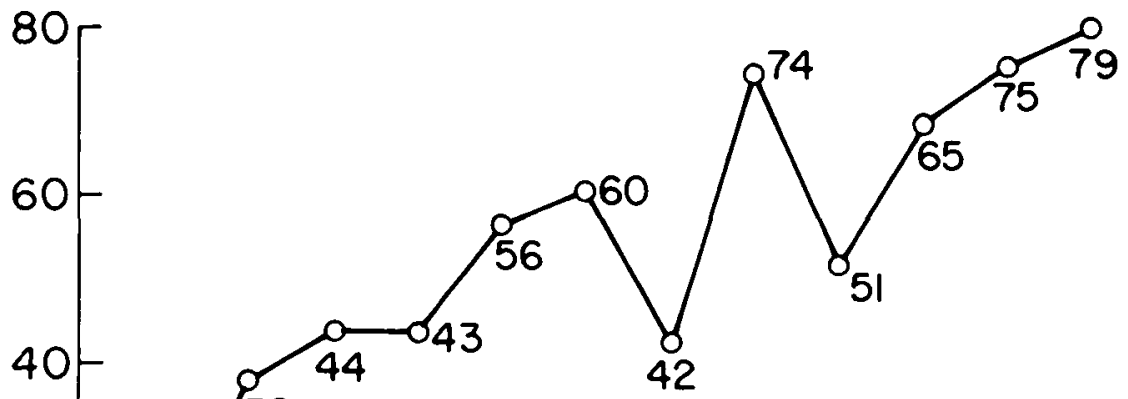

Figure 3-A typical individual curve of AD duration as a function of number of trials. Each trial is a $2 \mathrm{sec}$. stimulation delivered once per hour.

(SEP). These did not appear until several trials had gone by and until the AD began to lengthen. At first there were very few. Gradually the frequency of spontaneous EEG spikes or SEP's increased as kindling progressed. Somewhat similar events were described in the mammal by Goddard and Morrell (1971), Racine (1972b), Morrell (1973, 1974) and Wada and Sato (1974). However, in the mammal they appeared much later in the course of kindling, were less frequent, and did not exhibit the extraordinary constancy of waveform so striking in the frog (Morrell and Tsuru, 1975).

When SEP's first appeared in the inter trial record they began at the stimulation site ( $1^{\circ}$ focus) and were often, though not always, associated with an evoked spike at the $2^{\circ}$ region (Fig. 4B, E). The evoked spike was characterized by a smaller amplitude than the primary event, and followed it by an appreciable and constant delay (24-30 msec.). Eventually, SEP's appeared in the $2^{\circ}$ focus in the absence of any activity at the $1^{\circ}$ site (Fig. 4C, see arrows). Still later the high voltage discharges in the $2^{\circ}$ focus gave rise to the reverse propagation, ie., evoked spikes at the $1^{\circ}$ region (Fig. 4F). Thus, in Figure 4F the first complex was an independent $2^{\circ}$ SEP which elicited a small potential at the $1^{\circ}$ site while the second complex arose at the $1^{\circ}$ focus and fired the $2^{\circ}$ site. Transcommissural propagation of epileptiform activity took place in both directions.

Although SEP's, once begun, occurred roughly randomly throughout interstimulus intervals, they were much more frequent immediately after a stimulus delivery. For example, Figure 5 illustrates $20 \mathrm{~min}$. of continuous recording beginning shortly after the termination of stimulus-induced AD. Compare the density of spiking in Fig. 5A (first 5 min.) with that in 5D (last $5 \mathrm{~min}$.). The configuration of the spikes was also much more variable at times of high density (Fig. 6C) than it was during the remainder of the interstimulus interval (Fig. 6D).

Some time after consolidation of electrographically independent discharge in the two hemispheres, usu- 
A

$2^{\circ}$

post stim 2
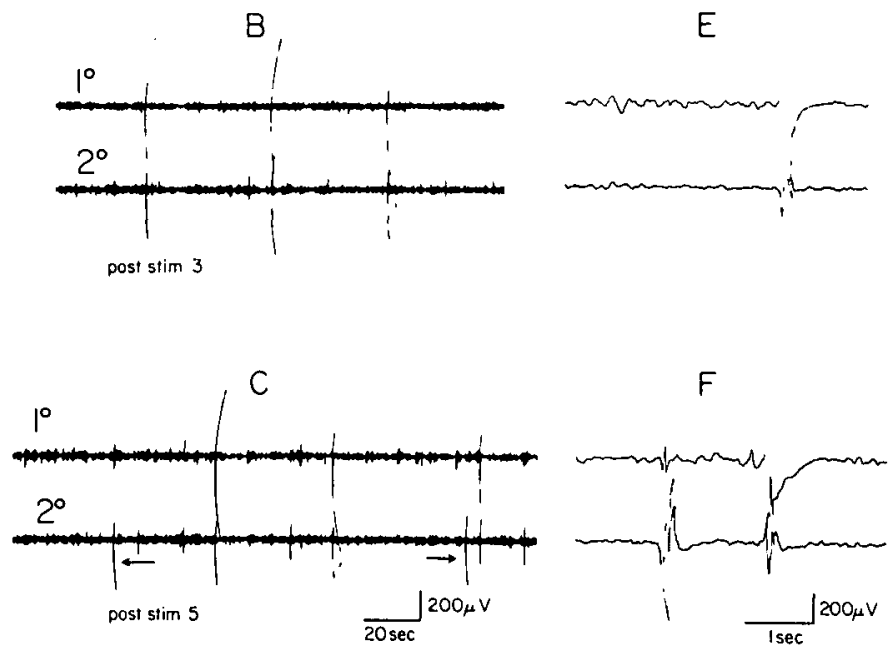

Figure 4-Acquisition of spontaneous epileptiform potentials during kindling. A, B. and $\mathrm{C}$ are taken at slow $(1 \mathrm{~mm} / \mathrm{sec}$.) paper speed; D, E and $\mathrm{F}$ at $25 \mathrm{~mm} / \mathrm{sec}$.
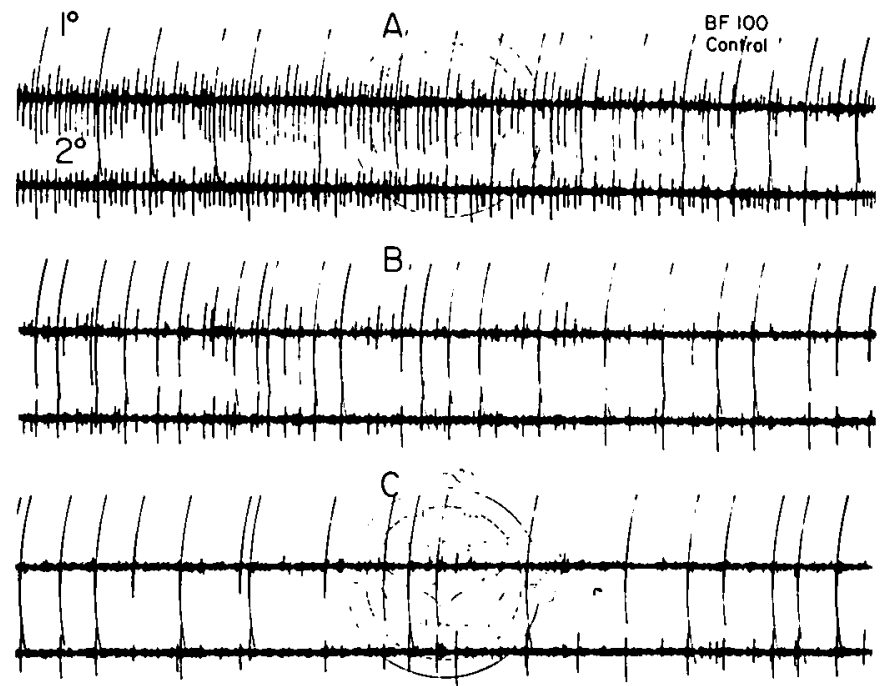

D

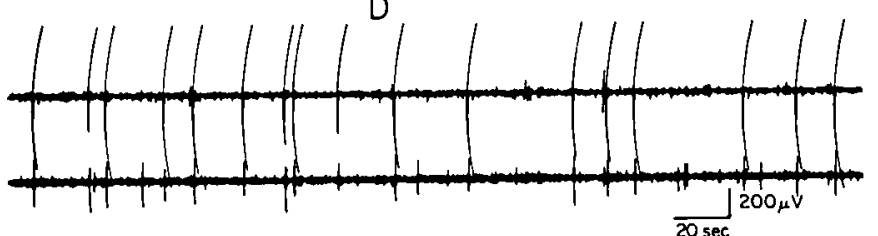

Figure 5-Continuous recording for $20 \mathrm{~min}$. after the end of an after-discharge late in kindling. Note the early high density of SEP's (A) which gradually taper off, B, C, D, over the $20 \mathrm{~min}$. interval . Counts of SEP's in the first 5 min., as in A, were the basis of the graphs in Fig. 10. ally between the 6th and 10th hour, the $1^{\circ}$ cortex was suppressed temporarily with topical Xylocaine. The resulting inactivation of the stimulation site and elimination of primary discharge did not cause the disappearance of SEP's in $2^{\circ}$ cortex. Indeed, the $2^{\circ}$ SEP's were dramatically enhanced (Fig. 7D, E). Figure 7A, B, $C$ illustrates the beginning of independent discharge in $1^{\circ}$ and $2^{\circ}$ regions after the 5th stimulation. After the 18th trial the discharge of the $1^{\circ}$ focus was eliminated by topical Xylocaine (Fig. 7D, E). In addition to the prompt augmentation of $2^{\circ}$ spike amplitude there was, of course, marked diminution of $1^{\circ}$ cortex responsiveness to $2^{\circ}$ focus firing. Upon removing the Xylocaine pledget and washing with saline, independent $1^{\circ}$ site SEP's reappeared and transmission resumed in both directions (Fig. 7F).

In summary, we have demonstrated all the criteria of kindling in the frog preparation. The entire sequence takes place within a $12-24 \mathrm{hr}$. time span.

\section{Protein Synthesis}

A detailed report of the biochemical data is now in preparation. For present purposes it will be sufficient to indicate the main findings.
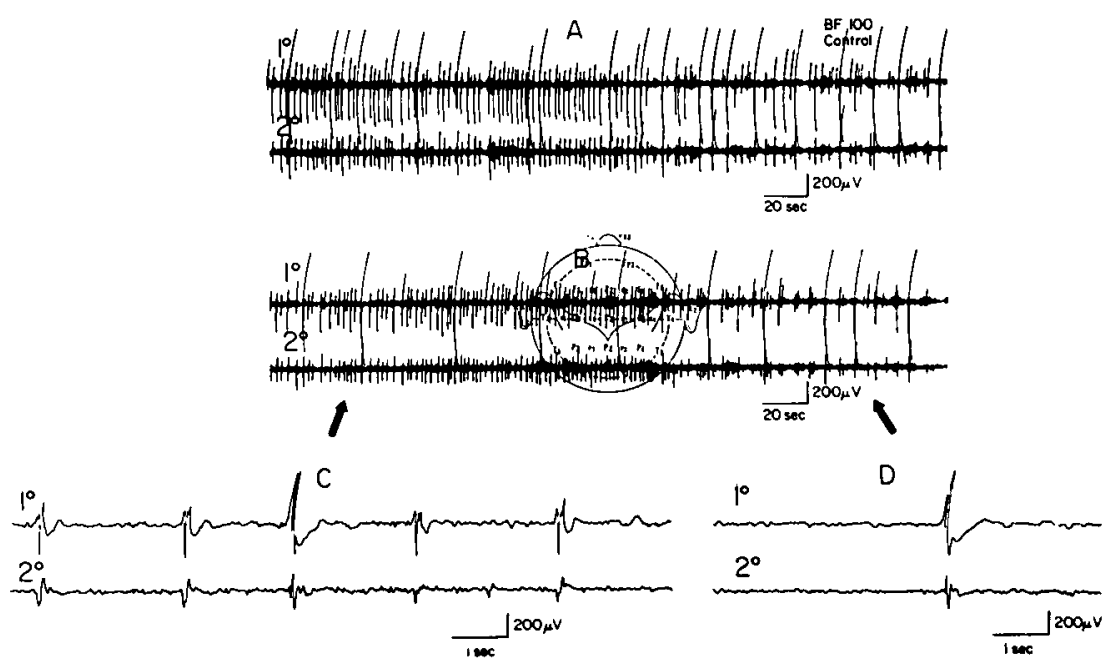

Figure 6-Configuration of SEP's during high density periods $(C)$ and lower density intervals (D). In the two examples, $A$ and $B$, at slow paper speed one can see the rapid decline in spike frequency in the first few minutes after an AD. Spike configuration is much more variable at times of high density (C) than when spikes are infrequent (D). 
${ }^{14} \mathrm{C}$ leucine. At a series of times ranging from 15 minutes to 72 hours groups of animals were sacrificed by decapitation, the brains removed in less than 2 minutes and processed as indicated under Methods. Radioactivity (counts/min./brain) was measured in both the protein fraction (TCA-insoluble pellet) and the supernatant which includes the pool of free leucine available for incorporation. A classical incorporation curve (see Brink et al., 1966) was obtained showing a sharp, rapid rise in the supernatant which then fell to a plateau in 5 hours. Counts in the protein fraction rose much more slowly reaching about $38 \%$ of the peak counts in 2 hours and continuing to rise for a full 24 hours.

\section{Inhibition of Protein Synthesis}

The glutarimide antibiotic cycloheximide (CXM) specifically blocks the binding of transfer RNA to polyribosomes as well as other steps in the reaction sequence by which

TABLE I

Inhibition of $\left({ }^{14} \mathrm{C}\right)$ leucine incorporation into brain protein by cycloheximide in Rana catesbeiana

\begin{tabular}{lcccc}
\multicolumn{1}{c}{ Animal } & $\begin{array}{c}\text { Protein } \\
\text { (counts/min/brain) }\end{array}$ & $\begin{array}{c}\text { Supernatant } \\
\text { (counts/min) }\end{array}$ & $\begin{array}{c}\text { Inhibition of } \\
\text { protein } \\
\text { synthesis }(\%)\end{array}$ \\
Controls $(\mathrm{n}=4)$ & 15375 & 27750 & 55.41 & \\
BF 120 & 1750 & 48000 & 3.64 & 88.6 \\
121 & 178 & 83880 & 0.21 & 98.8 \\
123 & 670 & 126800 & 0.53 & 95.6 \\
125 & 165 & 31570 & 0.52 & 98.9 \\
127 & 1873 & 111440 & 1.68 & 99.5 \\
132 & 522 & 166000 & 0.31 & 96.6 \\
133 & 214 & 59240 & 0.36 & 98.6
\end{tabular}

${ }^{*} \mathrm{P} / \mathrm{S}=\frac{\mathrm{cpm} \text { in protein }}{\mathrm{cpm} \text { in supernatant }}$

amino acids are transferred from aminoacyl transfer RNA into nascent peptides on ribosomes (Obrig et al., 1971). It has been extensively employed in both mammalian (Flexner et al., 1973; Barondes and Cohen, 1968) and non-mammalian (Agranoff, 1968) preparations for inhibition of cerebral protein synthesis.

Having established a normal incorporation curve for these animals,
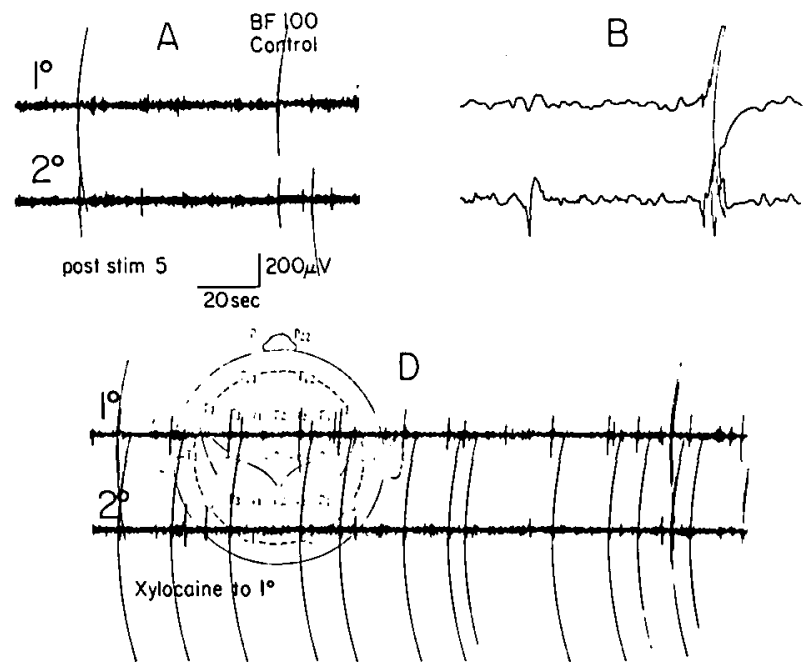

$F$

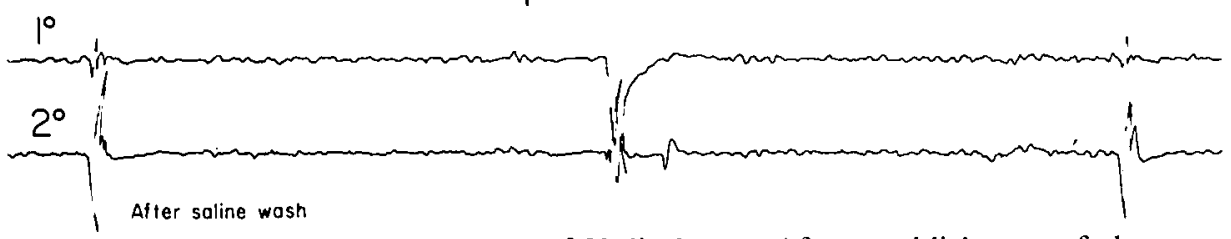

Figure 7-Testing for independence of $2^{\circ}$ discharge. After establishment of electrographically independent SEP $(\mathrm{A}, \mathrm{B}, \mathrm{C})$, the $1^{\circ}$ focus was suppressed with a cotton pledget soaked in $1 \%$ Xylocaine. The result was that (1) the $1^{\circ}$ focus ceased to fire spontaneously, (2) there was a marked augmentation in the amplitude and an increase in frequency of $2^{\circ} \mathrm{SEP}$ and (3) there was a marked diminution in $1^{\circ}$ cortex response to $2^{\circ}$ discharge (D and $E$ ). After removing the Xylocaine and washing with saline (F) spontaneous discharge resumed at the $1^{\circ}$ site $(F$, middle) and both sides exhibited independent SEP's. the extent and duration of cycloheximide-induced inhibition of incorporation of ${ }^{14} \mathrm{C}$ leucine was measured in another group of normal grass frogs.

Following an IP injection of cycloheximide $(50 \mathrm{mg} / \mathrm{kg})$ animals were given the isotope at intervals of 30 minutes, 2, 4.5, 7, 24, 37.5, 48 hours and decapitated 2 hours later. Again the detailed results will be reserved for another publication, but it is sufficient here to say that there was virtually complete inhibition at 30 minutes and at the 24 hour interval there was 98\% inhibition and at 48 hours inhibition was still $80 \%$.

These preliminary experiments indicated, therefore, that very substantial $(>90 \%)$ blockage of protein synthesis could be maintained for 24 hours with a single injection of the chosen dosage of CXM. Thus the duration of action was more than adequate to cover the time necessary for establishment of SEL in the frog.

As noted, kindling experiments were performed on the bullfrog, Rana catesbeiana, because the larger brain makes electrode placement easier. It was, therefore, necessary to verify for the bullfrog the biochemical results just described. Control animals $(n=4)$ receiving only the isotope and then sacrificed in 2 hours had average counts in the protein fraction of 15,373 and in the supernatant 27,750 for a P/Sx 100 of 55.41. In Table I these figures may be compared to those from the animals subjected to the kindling procedure. The experimental frogs were injected with CXM at least 1 hour before beginning brain stimulation. Stimulation at hourly in- 
tervals according to our usual kindling paradigm was then carried out for about 24 hours. Stimulation was then discontinued, animals were injected with the isotope and were sacrificed 2 hours later. Biochemical results are presented in Table I. At that time, i.e., 24 hours after CXM injection, inhibition of protein synthesis varied from 88.6 to $99.5 \%$.

\section{Effects of cycloheximide on behavior and EEG}

The cycloheximide had no obvious behavioral effects. In the grass frogs receiving CXM and in the experimental bullfrogs prior to spinal destruction there were no neurological deficits in terms of paralyses or defects in coordination, and light stimulation of the skin caused the usual withdrawal. Comparison of the background EEG of the treated animals with those of the control series did not reveal any abnormality to visual inspection. There was no gross slowing or flattening of the EEG. Electrical stimulation of brain using parameters usually employed resulted in typical after-discharge. Transcommissural evoked responses were present and appeared to be normal. Amplitude and wave-shape were not evaluated statistically so it is possible that subtle changes may have been missed (see Wilcox et al., 1974). Nevertheless, it seemed clear that there were no gross alterations in the usual indices of cerebral electrical activity.

\section{Effect of Cycloheximide on Kindling}

AD duration curves for the controls (open circles) and for the CXMtreated animals (closed circles) are illustrated in Figure 8. The points are the means for the two groups; the vertical bars are $95 \%$ confidence limits. A " $t$ " test was performed on the slopes of the regression lines for AD duration for each animal in both cycloheximide and control groups $\left(t=5.915, p=0.1205 \times 10^{-7}\right)$. Thus it would appear that kindling, as measured by progressive prolongation of AD duration with repeated stimulation, was markedly suppressed by cycloheximide.

The other available measure was the spontaneous epileptiform activ- ity, the SEP's. SEP's did occur in the treated animals but were limited to the hemisphere stimulated; no contralateral independent spikes were seen. The maximum development of the SEP in the CXM-treated animals included the occurrence of nonpropagating SEP's at the $1^{\circ}$ focus (Fig. 9B, E), its increasing frequency at the same site (Fig. 9C), and evidence of evoked activity in $2^{\circ}$ cortex (Fig. 9C, F) which never became independent and lagged the $1^{\circ}$ spike by 24-30 msec. The existence of evoked responses, of course, verifies the integrity of interhemispheric pathways, the persistence of electrical transmission and capability of the $2^{\circ}$ cortex to respond in a synchronized fashion.

Finally, the number of SEP's occurring in the first $5 \mathrm{~min}$. after cessation of after-discharge on each trial was counted in the two groups, giving a rough indication of SEP frequency. This measure, too, distinguished the cycloheximide-treated animals from the controls $\left(\mathrm{p}=0.6 \times 10^{-10}\right)$ (Fig. 10).

\section{DISCUSSION}

Since CXM treatment did not disturb background cerebral rhythms and did not interfere with either the

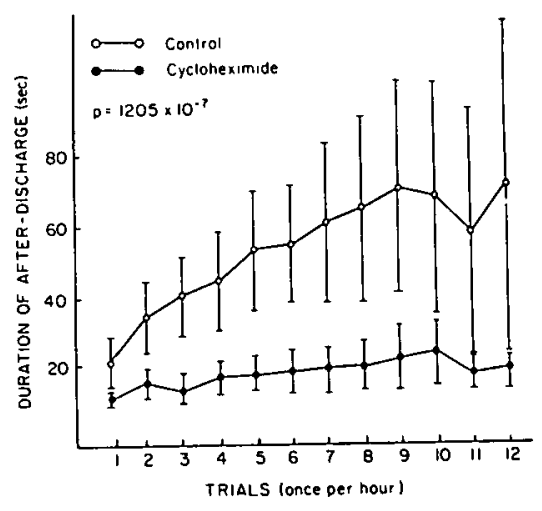

Figure 8-AD duration curves for the control and cycloheximide groups. The points represent the means and the vertical bars are $95 \%$ confidence limits. The curves are significantly different $\left(\mathrm{p}=.1205 \times 10^{-7}\right)$.

paroxysmal response to direct electrical stimulation or the transcommissural evoked potential, it seems likely that those processes involving action potentials and strictly neuroelectric events do not depend on protein synthesis, at least in any immediate sense. On the other hand, the neuroelectric events are apparently essential for kindling as shown by the fact that kindling can be blocked by phenobarbital (Wada et al., 1974) and diazepam (Racine et

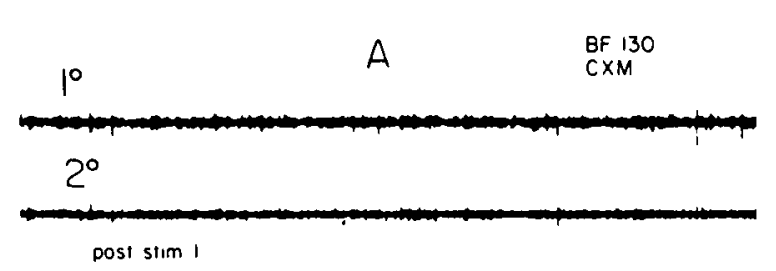

B

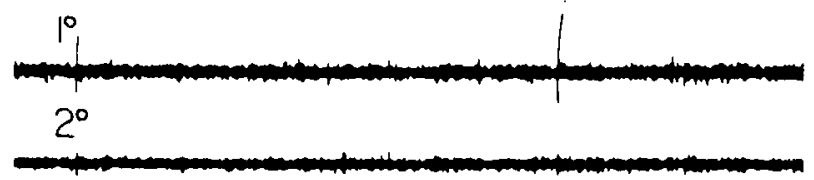

posi sitim 3

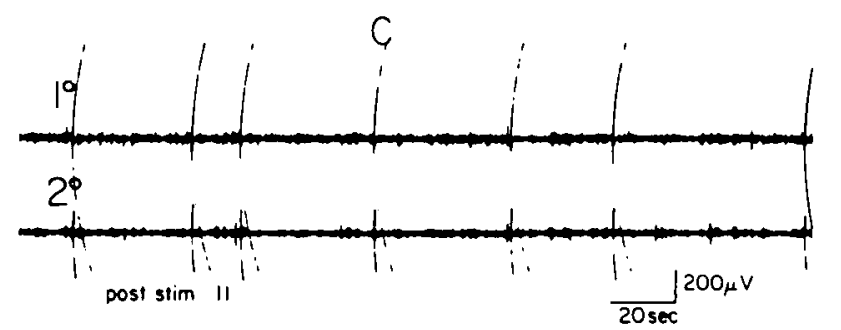

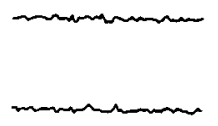

$E$
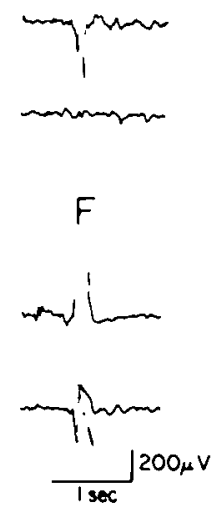

Figure 9-SEP's in a cycloheximide-treated animal. Spontaneous spikes only are seen on the $1^{\circ}$ side. All activity in the $2^{\circ}$ cortex was in the form of an evoked response to the $1^{\circ}$ spike. 
al., 1975) - drugs which interfere with the directly elicited AD. The neuroelectric events are essential but they do not appear to be enough. These experiments imply that protein synthesis is necessary as well.

Results thus far, however, cannot be taken as proof of the latter hypothesis. Cycloheximide does other things than inhibit protein synthesis. Flexner et al (1973) have shown a considerable inhibition of tyrosine hydroxylase activity in rats and mice receiving very high doses of CXM $(120 \mathrm{mg} / \mathrm{kg})$. Reduction of this enzyme would decrease the functional pool of norepinephrine. The likelihood that reduction of central catecholamine could account for a decrease in epileptogenesis goes against a substantial body of data which suggests that monoaminergic systems in brain act to suppress seizure activity and susceptibility (see reviews by Maynert, 1969 and Lovell, 1971). In fact, a convincing experiment by Corcoran et al., (1974) showed that depletion of catecholamine by 6-hydroxydopamine in rats resulted in more rapid kindling as well as in an exacerbated convulsive response to pentylenetetrazol challenge. Thus, it seems unlikely that the CXM effect on kindling is attributable to blockage of tyrosine hydroxylase.

There is some dispute over whether CXM interferes with RNA synthesis as well. Apparently it does so in rat liver at very high doses (three times those we used). Farber and Farmar (1973) indicate that the RNA effect is dose dependent, not merely a consequence of the inhibition of protein synthesis but a separate effect of very high doses of the drug. We are not aware of comparable studies in brain.

Obviously this research is only in its beginnings. Further consequences of cycloheximide will undoubtedly be found and have to be taken into account. Even if, indeed, it is the disruption of macromolecular synthesis which explains our result, that too, is only a beginning. Questions of the nature of the molecular species, how it is transported, and where and how it acts are all before us.

In introducing this work it was mentioned that the kindling technique, by substituting electrical stimulation for the chronic irritant, brought the entire process of secondary epileptogenesis under much more rigorous experimental control. Perhaps at this point it is appropriate to delineate precisely those components of this process we consider secondary. In doing so it is necessary to underscore the fact that we use the term secondary epileptogenic lesion to refer only to those neurological transformations which result in spontaneous and autonomous epileptiform behavior, demonstrably independent of the primary lesion, in cells that were untouched by the original epileptogenic agent. We do not consider the occurrence of evoked spikes or projected abnormality, no matter how far removed from the primary focus, as evidence for SEL.

When the electrical stimulus directly excites those neurons in the path of the imposed current, the cells discharge in a synchronized fashion and continue to do so for some seconds after the artificial current has ceased to flow. The events in these directly excited cells as well as the response of 2 nd order neurons driven by the $1^{\circ}$ cells we consider to be part of the primary epileptogenic process. However, the 2nd order neurons adjacent to the stimulus site as well as in distant regions have been synaptically rather than directly activated. Somehow this mediated activation is cumulative. Repeated stimulation results in a progressively more enhanced response. Properties of the 2nd order neurons are altered. Once kindling had occurred, Goddard et al. (1969) showed that a coagulation of tissue surrounding the stimulating electrode adequate to destroy all the directly affected neurons did not cause loss of the kindled response provided the current was increased sufficiently to activate surrounding 2nd order neurons. The surrounding cells exhibit anamnestic behavior; they "remember" their prior excitation. It is this cumulative effect and the recruitment of cells not directly affected by the original epileptogenic agent but, nevertheless, permanently transformed as a result of its action, that we regard as the core of secondary epileptogenesis.

Analogies between this process and those implicated in long-term memory were proposed as long ago as 1959 (Morrell et al., 1959; Morrell, 1961). Certainly a major interest of these data is the fact that CXM treatment abolishes long-term memory in behaving animals (Flexner et al., 1966; Barondes and Cohen, 1968; Agranoff, 1968). Whatever the mediating mechanism, therefore, it suggests again a close link between those neural events which underlie kindling and those which sustain long-term memory.

\section{ACKNOWLEDGMENT}

We thank Mitchell Passovoy for the statistical analyses.

Figure 10-Frequency of SEP's in the first 5 min. after cessation of AD on each trial. 


\section{DISCUSSION}

Dr. Wada: Both Drs. Corcoran and Fibiger have begun to examine the effects of cycloheximide upon kindling in rats, and I am glad to hear our hunch wasn't far off the mark according to your beautiful data. I have two questions: With the amount of cycloheximide that you use, (1) Does your frog remain capable of croaking? (2) Do you know what this agent might do to the other systems, such as catacholimines or GABA? Dr. Morrell: Yes, they do croak. However, we have not seen them eat and it seems to be the only thing that we haven't seen them do. I don't have any answers to the GABA system yet. We have just completed this part of the study so we don't have any information on that. Dr. Daly: Have you tried giving cycloheximide after establishing kindling in the frog? Dr. Morrell: That is a very good question, Dr. Daly. We haven't done that experiment yet, so we don't know. Dr. Racine: Retated to that last question, a fairly important control in this kind of work is to recover the animal from the drug treatment and then test them again to find out whether in fact you have blocked the apparent expression of the seizure response or in fact the development of the seizure response. Given that you did find the post-ictal events, that would be an important control, I think. In this case, have you done or are you planning to do something like that? Dr. Morrell: We haven't done the experiment but I would like to. That is, the proper control is to have them recover and see whether kindling has occurred as measured by afterdischarge duration in the presence of SHP's and those things. We have done that. We have electrically stimulated directly and we have seen convulsions occur in animals so that at least the neurocircuitry is there to mediate a convulsion. The real control has not been done yet. $D r$. Adamec: I was wondering if you tried adrenalectomising your frogs? The reason that I ask this is that you mentioned the cycloheximide effect on CER conditioning and Nakajima has recently reported that adrenalectomised mice do not show the memory deficit with cycloheximide injection. I was wondering if you would expect some difference in your kindling effects of the protein synthesis inhibitor if you adrenalectomised them? Dr. Morrell: That is a very interesting question. No, I have not adrenalectomised any frog. I don't know if I would even know where to look. Dr. Fernandez-Guardiola: It is a very well known fact that focal cortical electrical stimulation provokes evoked subcortical responses on a number of structures at the same time that the "Mirror Focus" is developing. Particularly sensible to weak stimulation of the motor cortex is the Red Nucleus. This structure, as well as the cerebellar Purkinje cell layer accelerates notoriously its spontaneous firing during the subthreshold cortical activation. My question is, did you detect any sub-cortical change of activity in your frogs during the rapid kindling, or as an effect of cyclohexemide administration? $\mathrm{Dr}$. Morrell: Wada has shown that there is a relationship between the appearance of the secondary focus and midbrain reticular discharge as well. We have not looked at the cerebellum out many years ago when we first started to play with this we thought that the transmission system was callosal and it turned out that if you cut the corpus callosum you abolish the secondary focus phenomenon. We then made what we call the callosal isolation: that is, we isolated the recipient cortex from all subcortical structures and intercortical structures leaving the callosal pathway intact. In those experiments we found that we could not develop an independent mirror focus, so it seems clear that at least two pathways are required. Wehther it is subcortical or via the cerebellum, I don't know, but the callosal pathway by itself is not enough. Dr. Stevens: I want to ask you a question regarding the catecholamines, I am sure that you plan to go ahead with blocking specific catecholamine enzymes such as using AMPT. Has anyone done anything with that? Dr. Morrell: No, not that I know of. Dr. Stevens: With respect to one of the previous papers, I was interested in the comments on visual cortex kindling. I just wanted to mention that at this moment, one strange thing about the visual cortex is that you can't get an epileptic focus going in it with aluminum hydroxide either, as you probably know, although if you then make a midbrain lesion you can. I wonder if those parts that I think are epileptic are partly deafferented producing these hypersynchronized potentials. I wonder if a visual cortex can kindle following deafferentation of the cortex, for example, blinding the animal or cutting the optic nerves. That's in the human, at least, when we see spikes spontaneously in the visual cortex so that one might then potentiate the possibility of kindling? Dr. Morrell: If by deafferentation you mean deafferentation supersensitivity, I think that it is very unlikely to play an important role here. You can take one hemisphere out and the other hemisphere doesn't get epileptic. Massive degeneration can occur in a system and you don't really see spontaneous epilepsy following a hemispherectomy. Spontaneous epilepsy does not occur in the other side. I do think that there is an important influence of afferent input into the area. We know that if you knock out the reticular formation you can increase the incidence of epileptiform activity in the cortex and if you knock out the specific sensory pathway to a sensory area you can increase the incidence of spikes. Isn't that simply reducing the level of desynchronizing input into the area and allowing greater synchronization to develop? I think Wada has done some studies on this. Dr. Daly: Kellaway was unable to create spikes in the occipital cortex of kittens by enucleation of their eyes, that is, by trans-synaptic deafferentation. He did observe spikes in children with ocular abnormalities, not all of whom were blind. $D r$. Racine: In response to Dr. Steven's comment, we have done an experiment similar to the one you described. In an attempt to test the effects of deactivation on striate cortex sensitivity, Dr. Karl Gijsbers and I looked at epileptiform afterdischarge threshold in areas 17 and 18 of rats enucleated 2 weeks previously. We also looked at electrographic kindling, motor seizures rarely develop with posterior neocortex stimulation. We found no differences between enucleated and control rats in any of the measures used. Dr. Penry: Are we certain that the occipital cortex cannot be kindled? Dr. Hambrecht and others working on the visual prosthesis project have found the seizures after stimulating the occipital cortex in man and animals. Dr. Wada: Some years ago we studied the effect of deafferentation upon cerebral epileptogenicity as manifested by the development of the aluminum hydroxide focus. In this study we found that visual deafferentation by means of optic tractotomy in cats markedly accentuated the development of the aluminum hydroxide focus in contrast to cochlea destruction which appeared to interfere with the ripening process of epileptogenicity. In the Senegalese baboon. Papio papio, we also observed evidence of increased seizure susceptibility of posterior cortices by sectioning the hemisphere at the mid portion, thus dividing it into anterior and posterior halves down to the diencphalic region bilaterally. In intact baboons, flicker stimulation will initially evoke sustained spike discharge in the pontine reticular formation before manifesting clinical myoclonic response which is coincidental with the anterior but not posterior cortical discharge. Following anterior-posterior divisions of the hemisphere, flicker stimulation will produce very definite and localized electrographic discharge in the visual, but not the anterior, cortex to which no surgical damage was done. These findings seem to suggest that deafferentation super sensitivity does interact significantly with the seizure enhancing factor such as generalized (Papio papio) or localized (aluminum hydroxide) epileptogenic predisposition in terms of creating increased visual cortical seizure susceptibility. I really do not see why kindling cannot take place from the posterior cortices. It is relatively easy to say something positive but one has to be careful when the result is negative. In our prefrontal kindling we could have said baboons cannot be kindled from the prefrontal cortices if we applied the yardstick of the completion of amygdaloid kindling (average 72 days) since it took more than an average of 126 days to develop initial motor manifestations and over 300 days to reach the final stage. With patience, I feel quite certain you will observe a seizure development from the posterior cortices. Indeed, a recent survey by Dr. Ajmone-marsan has shown that occipital epileptogenic activity may propagate to a number of cortical and/or sub-cortical structures culminating in any one of a large combination of ictal sensory or motor manifestions. Dr. Goddard: I would like to come back to the topic of Dr. Morrell's talk and to go a little further than Adamec. The notion of removing the adrenals may sound very strange, but it may not be nearly as strange as you might think. The reason for it is that cycloheximide is necessary for protein synthesis and cortical steroids are not held in reserve in the adrenal. Therefore, they have to be synthesised on demand and there will be no cortical steroid feedback to the brain. Nakajima and Cottrell show that you can get these learning deficits with cycloheximide provided that you have not removed the adrenals or you can reverse the learning effects of cycloheximide by injection of cortical steroids and that you can do that same thing by injecting a low level of cortical steroids into the hippocampus which raises the perhaps crazy but nevertheless interesting possibility that the reason why you cannot develop your kindling in the hippocampus in the frog treated with cycloheximide may have something to do with cortical steroids as well as the other possibilities that have been listed. 


\section{REFERENCES}

AGRANOFF, B. W. (1968). Biological effects of antimetabolites used in behavioral studies. In: D. H. Efron et al. eds "Psychopharmacology: A Review of Progress, 1957-1967." PHS Publ. 1836, pp. 909-917. Wash., D.C. U.S. Govt. Printing Off.

BARONDES, S. H. and COHEN, H. D. (1968). Memory impairment after subcutaneous injection of acetoxycycloheximide. Science 160: 556.

BRINK, J. J., DAVIS, R. E. and AGRANOFF, B. W. (1966). Effects of Puromycin, Acetoxycycloheximide and Actinomy. cin $\mathrm{D}$ on protein synthesis in goldfish brain. J. Neurochem. 13: 889-896.

CORCORAN, M. E., FIBIGER, H. C. MCCAUGHRAN, J. A. Jr. and WADA, J. A. (1974). Potentiation of amygdaloid kindling and Metrazol-induced seizures by 6-Hydroxydopamine in rats. Exptl. Neurol. 45: $118-133$

FARBER, J. L. and FARMAR, R. (1973). Differential effects of cycloheximide on protein and RNA synthesis as a function of dose. Biochem. Biophy. Res. Commun. 51: 626-630.

FLEXNER, L. B., FLEXNER, J. B. and ROBERTS, R. B. (1966). Stages of memory in mice treated with acetoxycycloheximide before or immediately after learning. Proc. Nat. Acad. Sci. USA 56: 730-735.

FLEXNER, L. B., SEROTA, R. G. and GOODMAN, R. H. (1973). Cycloheximide and Acetoxycycloheximide: Inhibition of Tyrosine Hydroxylase activity and amnestic effects. Proc. Nat. Acad. Sci. USA 70: 354-356.

GODDARD, G. V. (1967). The development of epileptic seizures through brain stimulation at low intensity. Nature 214: 1020.

GODDARD, G. V., McINTYRE, D. and LEECH, C. (1969). A permanent change in brain function resulting from daily electrical stimulation. Exp. Neurol. 25: 295-330.

GODDARD, G. V. and MORRELL, F. (1971). Chronic progressive epileptogenesis induced by focal electrical stimulation of brain. Neurol. 21: 393.

GUERRERO-FIGUEROA, R., deBALBIAN, V. G., BARROS, A. and HEATH, R. G. (1964a). Cholinergic mechanism in subcortical mirror focus and effects of topical application of gamma aminobutyric acid and acetylcholine. Epilepsia 5: 140-155.

GUERRERO-FIGUEROA, R., BARROS, A. and HEATH, R. G. (1964b). Experimental subcortical epileptiform focus. Epilepsia 5: 112-139.

HOLUBAR, J., STREJCKOVA, A. and SERVIT, Z. (1966). Penicillin and mirror epileptogenic foci in the brain hemisphere of the frog. In: Comparative and Cellular Pathophysiology of Epilepsy, edited by $Z$. Servit. Excerpta Medica International Congress Series 124, Amsterdam. 214-220.

LOVELL, R. (1971). Some neurochemical aspects of convulsions. In: Handbook of Neurochemistry. Vol. 6: Alterations of Chemical Equilibrium in the Nervous Sys- tem. A. Lajtha, ed. Plenum Press, New York, pp. 63-102.

MAYNERT, E. W. (1969). The role of biochemical and neurochemical factors in the laboratory evaluation of antiepileptic drugs. Epilepsia 10: 145-162.

MORRELL, F. (1959). Experimental focal epilepsy in animals. Arch. Neurol. 1: 141-147.

MORRELL, F. (1960). Secondary epileptogenic lesions. Epilepsia 1: 538-560.

MORRELL, F. (1961). Electrochemical mechanisms and information storage in nerve cells. M.I.T. Seminar-Lecture Series, In: Molecular Specificity and Biological Memory, F. O. Schmitt, Ed. pp. 73-79.

MORRELL, F. (1961). Lasting changes in synaptic organization produced by continuous neuronal bombardment. In: CIOMS Conference on Brain Mechanisms and Learning, J. F. Delafresnaye, A. Fessard and J. Konorski (Eds.), Blackwell Scientific Publications, Oxford, pp. 375-392.

MORRELL, F. (1969). Physiology and Histochemistry of the Mirror Focus. In: Basic Mechanisms of the Epilepsies. Eds.: H. H. Jasper, A. A. Ward, and A. Pope. Little, Brown Co., Boston, pp. 357-370.

MORRELL, F. (1973). Goddard's Kindling Phenomenon: A New Model of the "Mirror Focus", Chemical Modulation of Brain Function, Edited by H. C. Sabelli, Raven Press, New York, pp. 207-223.

MORRELL, F. (1974). Animal Models of Human Focal Epilepsy. In: H. L. Klawans, ed. Models of Human Neurological Diseases, Excerpta Medica, Amst. pp. 167-199.

MORRELL, F. and BAKER, L. (1961). Effect of drugs on secondary epileptogenic lesions. Neurology 11: 651-664.

MORRELL, F. and FLORENZ, A. (1958). Modifications of the freezing technique for producing experimental epileptogenic lesions. Electroenceph. clin. Neurophysiol. 10: 187 .

MORRELL, F., PROCTOR, F. and PRINCE, D.A. (1965). Epileptogenic properties of subcortical freezing. Neurology 15: 744-751.

MORRELL, F., SANDLER, B. and ROSS, G. (1959). The "mirror focus" as a model of neural learning. Proc. XXI Internat. Congress Physiol. Sciences, Buenos Aires, p. 193

MORRELL, F. and TSURU, N. (1974). Development of spontaneous hypersynchrony in the hippocampal cortex of the bullfrog, Rana catesbeiana. The Biological Bulletin, 147: 492.

MORRELL, F. and TSURU, N. (1975). Kindling in the Frog: Development of Spontaneous Epileptiform Activity. Electroencephalog. clin. Neurophsyiol. In Press.

OBRIG, T. G., CULP, W. J., McKEEHAN, W. C. and HARDESTY, B. (1971). The mechanism by which cycloheximide and related glutarimide antibiotics inhibit peptide synthesis on reticulocyte ribosomes. J. Biol. Chem. 246: 174-181.

PINEL, J. P. J., PHILLIPS, A. G. and DEOL, G. (1974). Effects of current intensity on kindled motor seizure activity in rats. Behav. Biol. 11: 59-68.

PURPURA, D. P., PENRY, J. K., TOWER, D. B., WOODBURY, D. M. and WALTER, R. D. editors (1972). Experimental Models of Epilepsy - A Manual for the Laboratory Worker. Raven Press, New York. pp. 615.

RACINE, R. J. (1972a). Modification of seizure activity by electrical stimulation. I. After-discharge threshold. Electroenceph. clin. Neurophysiol. 32: 269-279.

RACINE, R. J. (1972b). Modification of seizure activity by electrical stimulation. II. Motor Seizure, Electroenceph. clin. Neurophysiol. 32, 281-294

RACINE, R. J. (1975). Modification of seizure activity by electrical stimulation: cortical areas. Electroenceph. clin. Neurophysiol. 38: 1-12.

RACINE, R. J., LIVINGSTON, K. and JOAQUIN, A. (1975). Effects of procaine hydrochloride, diazepam and diphenylhydantoin on seizure development in cortical and subcortical structures in rats. Electroencephalog. clin. Neurophysiol. 38: 355-365.

TANAKA, A. (1972). Progressive changes of behavioral and electroencephalographic responses to daily amygdaloid stimulations in rabbits. Fukuoka Acta Med. 63: 152-164.

TRESS, K. H. and HERBERG, L. J. (1972). Permanent reduction in seizure threshold resulting from repeated electrical stimulation. Exp. Neurol. 37: 347-359.

WADA, J. A. (1964). Longitudinal analysis of chronic epileptogenic brain process. In: Wada, T. (ed). Epileptology-Clinical and Basic Aspects. Igaku Shoin Ltd. Tokyo, p. 426-453.

WADA, J. and CORNELIUS, L. (1960). Functional alterations of deep structures in cats with chronic irritative lesions. Arch. Neurol. 3: 425-447.

WADA, J. A. and SATO, M. (1974) Generalized convulsive seizures induced by daily electrical stimulation of the amygdala in cats. Neurology 24: 565-574.

WADA, J., SATO, M. and GREEN, J. (1974). Anticonvulsive and prophylactic potency of antiepileptic agents: Assessment by amygdaloid kindling preparations in cats. Epilepsia 15: 276

WILCOX, G. L. Jr., ANDRY, D. K. and LUTTGES, M. W. (1974). Cycloheximide effects on electroencephalographic and evoked responses in mice. Behavioral Biology 12: 81-92.

WILDER, B. J. (1972). Projection Phenomena and Secondary Epileptogenesis - Mirror Foci. In: Experimental Models of Epilepsy - A Manual for the Laboratory Worker. D. P. Purpura, J. K. Penry, D. B. Tower, D. M. Woodbury, R. D. Walter eds. Raven Press, New York, 85-111.

WILDER, B. J. and MORRELL, F. (1967a). Secondary epileptogenesis in the frog forebrain. Neurology 17: 1041-1051.

WILDER, B. J. and MORRELL, F. (1967b). Cellular behavior in secondary epileptic lesions. Neurology, 17: 1193-1204. 